\title{
Translation, Betrayal and Ambiguity in IS Development
}

\author{
Jim Underwood \\ Department of Information Systems, University of Technology, Sydney, PO Box 123, \\ BROADWAY, 2007, AUSTRALIA, jim@it.uts.edu.au, Phone: +61295141831 Fax: +6129514 \\ 1807
}

Abstract: This paper uses semiotic theories to model how meaning is constructed during an IS development project. Conventionally, shared meanings among all project stakeholders are regarded as a prerequisite for success. Based on an analysis of documents relating to a flexible learning pilot project developed at an Australian university, a model of meaning was built combining actor-network theory and Foucault's theory of discourse. Important scripts were identified from internal working documents and their meaning discussed with a variety of human actors. Scripts within the actor network were interpreted with reference to expert discourses familiar to the various actors. Further analysis using this model shows how mistranslation can occur in at least two distinct ways as scripts pass between actors; through apparent acceptance of espoused scripts and the pragmatic betrayal of scripts-in-use. In our case study project these two types of mistranslation were used to maintain ambiguity over certain key issues throughout the life of the project, and this ambiguity contributed significantly to project's success.

Key words: Information systems development, Actor-network theory, Foucault, Ambiguity

\section{INTRODUCTION}

Organisational semiotics deals with the use of signs and the construction of shared meaning within and among enterprises (Stamper 1992). The idea of organisational semiotics can be applied to information systems research in two ways. Firstly, information systems in operation can be seen as sign carriers, providing one of the channels through which meaning is shared.

The original version of this chapter was revised: The copyright line was incorrect. This has been corrected. The Erratum to this chapter is available at DOI: 10.1007/978-0-387-35611-2_22 
Secondly, and this is the focus of our current research, the process of designing and building new information systems seems to depend on establishing shared meanings among users, technical experts and other stakeholders. This sharing is mediated through signs, usually words and diagrams, used in conversations, meetings, electronic mail and formal documentation.

The overall objective of our research is to understand in actual IS development projects the extent to which this sharing of meaning succeeds, how it is accomplished, what barriers there are to constructing shared meaning, whether all stakeholders can contribute equally to this construction and the consequences for project development when this construction fails.

Our work is based on a case study conducted at an Australian university. A team comprised mainly of academics plus two consultants worked on a project (known as the Flexible Delivery Pilot Project) to produce a framework (or perhaps prototype) for supporting flexible learning within the university. This was mainly seen as providing some web based support for teaching and learning for students who would still attend campus for some of their learning. All team members continued their other full time responsibilities while working on the project. The project had a planned life of one year and a budget of AUD 75,000.

The research was carried out as a case study. The primary data sources were official documents, working papers, electronic mail and minutes of team meetings. These were supplemented and clarified through interviews with project team members. The researcher is not an employee of the university being studied. In this paper we concentrate on presenting a model of meaning which we developed during the case study. This model is based on both actor-network theory and Foucault's theory of discourse. The model concentrates on the translation of statements (usually related to requirements) as they pass among stakeholders of the system. Mistranslation leads to ambiguity in the shared "understanding" of the system, but this is not necessarily detrimental to system success.

In the following section we give a brief introduction to some established theories of meaning and show how we use actor-network theory as the foundation for studies of meaning in IS development. We then show how these theories needed to be adapted as we attempted to apply them to the case study. Our penultimate section models the translation of scripts in more detail, and we conclude with a brief discussion of possible practical applications of our findings. 


\section{DEVELOPING A SUITABLE THEORY OF MEANING}

The commonsense view of semiotics (the theory of signs) is that signs represent things in a world of objects, actions and relationships. One wellknown model of how this representation operates was developed by Charles Peirce.

A sign, or representamen, is something which stands to somebody for something in some respect or capacity. It addresses somebody, that is, creates in the mind of that person an equivalent sign, or perhaps a more developed sign. That sign which it creates I call the interpretant of the first sign. The sign stands for something, its object. It stands for that object, not in all respects, but in reference to a sort of idea, which I have sometimes called the ground of representation. (Peirce Collected Papers of C.S. Peirce (2.228) quoted in Spinks 1991)

The triadic nature of this definition is captured in the following diagram based on Ogden and Richards (Nöth 1990:89).

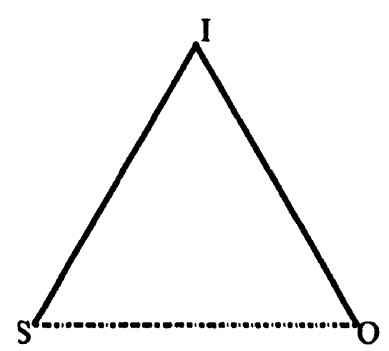

Figure 1. Triadic Sign

Here we use the terms sign vehicle ( $\mathrm{S}$ - and sometimes abbreviated to sign where there is no ambiguity), interpretant (I) and object (O). The complete triad is called the sign (or sign occurrence for emphasis). This terminology is close to that used in Spinks (1991:6) for his semiotic pyramid, and corresponds to that of Peirce except that "representamen" is replaced by the more evocative "sign vehicle". Spinks comments that three solid lines would give a better impression of the fundamental nature of the triad. The dotted line can give the (non-Peircean) impression that the triad is reducible to two dyads, so that the relationships between sign vehicle and interpretant, and interpretant and object, could exist independently. Nevertheless, the current arrangement does convey the central role of the interpretant (often thought of as the meaning). Peirce never makes clear the ontology of the interpretant, what type of thing it is. His theory is 
pansemiotic - everything is a sign, figure 1 is recursive, and the world of meaning is an infinite network of these diagrams linked together.

The basic structure of Peirce's theory is radically subjective. Signs have existence only as triads, the interpretant is central, and so, logically, there is no possibility of correct or incorrect interpretation; each sign occurrence is unique and cannot be resolved into components which it might share with other signs. A red flag may mean "danger, roadwork", may stand for socialist revolution, or may be merely a lost object (Chaplin 1936). Peirce deals with this through the concepts of final interpretant, the "proper" meaning on which all interpreters will converge, and general sign, which is understood through objective consensus, not individual thought (Oehler 1987:6). Thus subjectivity is avoided through a context which is partly social (consensus) but which is objectified through the infinite network of sign interpretants.

The idea of an interpretive network is of little practical use unless we can give specific form to this network. Foucault's contribution to this problem was to examine a number of specialised networks of meaning, including those of medicine and economics. He began this work with an interest in the rules for discussion and for determining truth, but from an historical perspective and on a grand scale. The approach taken in his early work is often labelled archaeology.

By archeology I would like to designate not exactly a discipline, but a domain of research, which would be the following: In a society, different bodies of learning, different philosophical ideas, everyday opinions, but also institutions, commercial practices and police activities, mores - all refer to certain implicit knowledge (savoir) special to this society. This knowledge ... is what makes possible at a given moment the appearance of a theory, an opinion, a practice.... and it's this knowledge I wanted to investigate, as the condition of possibility of knowledge (connaissance), of institutions, of practice. (Foucault 1989:13)

Foucault wished to avoid giving explanations in terms of interests, competing arguments, political alliances, personalities or accidents of history; he wanted (in the case of economics, for instance) to define "the conditions on the basis of which it was possible to conceive of both 'physiocratic' and 'utilitarian' knowledge in interlocking and simultaneous forms" (Foucault 1971:200). People within one discipline who have opposing views, as well as those working in other disciplines, all share an underlying approach to knowledge and practice. In the disciplines of Enlightenment Europe, for instance, Foucault detected a common orientation towards classification. 
These investigations were based on archival studies of documents, analysed at the level of statements. Foucault sees a sentence as a grammatical construct and a proposition as a truth claim about the world; a statement has a similar form, but its significance is its appearance in documents. But what are these statements about? Intuitively, some might be about medicine, some about economics, even if both occur in, say, government reports. How can we accurately group statements into coherent domains? Some possible principles for classifying statements are that they are about a particular object or objects, they use statements of a certain form, they concentrate on defining particular key terms, or they have a coherent history. Foucault rejects each of these in turn; the first, for instance, because the objects are themselves created or defined by networks of statements. Foucault concludes that it is best follow the build up of networks of statements through chains of differences. Within the discourse of data modelling, for example, a conversation (or series of journal articles) may move from distinguishing between objects and entities, to discussions of entities versus relationships, to distinctions between entities and records (Hawryszkiewycz 2001). These distinctions are discussed continually precisely because they have at the time no universally accepted definitions within the discipline. Foucault calls these chains of unresolved issues systems of dispersion. The set of all statements which are linked in this way form a discursive formation, which is rather like a science, discipline or theory. (Foucault 1972:31-39) (Note: We will frequently call this discursive formation a discourse and we will refer to this part of Foucault's work as discourse theory. This is quite a different use from that in some areas of pragmatic linguistics such as conversation analysis and sociolinguistics, where a discourse is a segment of conversation. When we need to refer to this more common usage we will call it discourse analysis.)

Most of Foucault's work is based in the Modern era, which he dates from around 1800 , when interest became focussed on the structure of discourses themselves rather than their referents. With this shift knowledge became both superficial and transcendental, with endless measurement of everything which can be perceived (through whatever instrument) combined with the incomprehensible "metaphysics of that never objectifiable depth from which objects rise up towards our superficial knowledge" (Foucault 1971:245). And signs themselves had become problematical, and they and their makers had become objects of study:

negatively, the domain of the pure forms of knowledge becomes isolated, attaining both autonomy and sovereignty in relation to all empirical knowledge, causing the endless birth and rebirth of a project to formalize the concrete and to constitute, in spite of everything, pure sciences; 
positively, the empirical domains become linked with reflections on subjectivity, the human being, and finitude, assuming the value and function of philosophy, as well as the reduction of philosophy or counterphilosophy. (Foucault 1971:248)

This reversal of empiricist "common sense", with objective truth judged against a rigorous formal version of reality, while specific instances of formal reality are taken to be subjective events, is the dilemma of modernism. While the modern period is often thought to have ended around 1920 its approach to knowledge is still profoundly influential in many fields. In Information Systems the modernist dilemma affects both theory and practice. IS theory vacillates between detailed model building (Falkenberg $e t$ al 1995) and a wide-ranging search for philosophical foundations (Winder $e t$ al 1997). IS practice must deal with both complex information architectures and the everyday actions and attitudes of system users.

We approached our case study with the idea that various stakeholders of the systems development project would base their understanding in different discourses, such as computer science and education. This would make constructing common meanings difficult and could lead to project failure. The theoretical difficulties with our approach were that Foucault seldom discusses interactions among discourses and that discourses are seen as very stable. An individual might be converted from one discourse to another, as when a user representative becomes an enthusiastic advocate of some technology, but there is still no mixing of the discourses.

These difficulties lead us to Deleuze and discursive rupture (Deleuze \& Parnet 1987:143-144). This can occur when large numbers of converts are incompletely absorbed and produce mutations or ambiguity in the discourse, or when several discourses coexist with a veneer of agreement which is lifted when shared understanding is required for practical activities.

In both cases there appear what Deleuze calls lines of flight. These are directions which meaning might follow, where it might break away from the discipline of discourse. A number of possibilities follow. The dominant discourse may recapture meaning by overcoding, by forcing the situation into a standard mould. At the power/knowledge level (Foucault 1980) the issue may be ignored or covered over for individual reasons (micropolitics). (Deleuze \& Parnet 1987:143-144) A new discourse may develop (much quicker than Foucault would have thought) and implement its own overcoding to establish stability. Or we might settle on a plateau which is "a continuous, self-vibrating region of intensities whose development avoids any orientation toward a culmination point or external end" (Deleuze \& Guattari, 1988:22). Or, more disturbingly: 
Each "plateau" is an orchestration of crashing bricks extracted from a variety of disciplinary edifices. They carry traces of their former emplacement, which give them a spin defining the arc of their vector. The vectors are meant to converge at a volatile juncture, but one that is sustained, as an open equilibrium of moving parts each with its own trajectory. (Brian Massumi, forward to Deleuze \& Guattari 1988:xiv)

In studying systems development projects this metaphor can be most illuminating.

\section{MODIFYING THEORY TO MATCH THE CASE}

After we had selected a case study and began examining documents and interviewing stakeholders some practical difficulties with our approach became apparent. The most obvious was that this was a user-developed system, so that it was not possible to separate stakeholders into disciplines attached to different reference discourses. It quickly became clear, however, that individual stakeholders were frequently switching roles, so that they would make statements first from one discourse, later from another; at the level of statements the interaction of discourses could be still examined. A more serious problem was that interviewees were unwilling to discuss the meaning of what to the researcher seemed to be key concepts or words. Ambiguity and conflicting interpretations which seemed important and obvious were almost wilfully ignored by participants. One example was the phrase "flexible delivery" which featured in the name of the project. This phrase has been the subject of extensive discussion within the Australian tertiary education sector, and is regarded by some educationists as a theoretically vacuous betrayal of the more radical concept "flexible learning". During interviews project participants were asked for their definitions of these terms. No one was prepared to provide definitions and several claimed the terms were in practice interchangeable, although all were clearly aware of the controversy and several offered opinions about what others thought. It appeared that on this point everyone had "agreed to disagree" for the duration of the project. Conventional wisdom is that this will lead to disaster (Stamper 1973:72). Our third difficulty was, however, that although no readily identifiable software product had been produced, most stakeholders regarded the project as a success. Could success and ambiguity be positively correlated?

To deal with these difficulties we needed to expand our theoretical horizons, and at this stage discovered actor-network theory (ANT), which was originally developed as a method in science and technology studies. 
ANT allows us to model the practical development of networks of meaning by granting status to hybrids or quasi-objects which are heterogeneous networks of phenomena. Perhaps the most infamous feature of ANT is that actors, the components of networks, may be more or less interchangeably people, animals, plants, organisations, machines, events or ideas. The hole in the ozone layer, for instance, "links the most esoteric sciences and the most sordid politics, the most distant sky and some factory in the Lyon suburbs, dangers on a global scale and the impending local elections or the next board meeting" (Latour 1993:1). Similarly, a management information system is "an integrated user-machine system for providing information to support operations, management, and decision-making functions in an organization. The system utilises computer hardware and software; manual procedures; models for analysis, planning, control and decision making; and a database." (Davis \& Olsen 1984:6) By tracing the activity of these hybrid networks we can see how the world is interpreted, reinterpreted and changed. In some ways ANT is a type of stakeholder analysis where the stakeholders may be other than the usual people and organisations and the stakes may be reinterpreted as negotiations progress. Some key concepts of ANT are actor, script and translation.

One way that ANT can be used to follow the fortunes of a project is through tracing the development of alliances among actors. In his study of scallop fisheries Callon looks at manipulating actor-networks from one point of view: "... the capacity of certain actors to get other actors - whether they be human beings, institutions or natural entities - to comply with them depends upon a complex web of interrelations in which Society and Nature are intertwined" (Callon 1986:201). Callon sees translation (of exactly what is not made clear in Callon's paper) as a progression through four stages or "moments" which attempts to coopt the other actors to the project in question. (The apparent vagueness in a lot of actor-network theory is designed to concentrate attention on activities in the network and avoid statements which could mistakenly be taken as making ontological claims.) These moments are problematisation (which defines the project as something useful), interessement (attracting the attention of potential supporters), enrolment (gaining commitment, resources and effort) and mobilisation (promoting the finished product to a wider audience). This sequence of steps mirrors common cooption strategies, its main novelty being the heterogeneous collection of actors involved. Of course the process can fail at any stage and it may be necessary to back track if previous commitments weaken.

According to ANT, actors are attached to a project through scripting and as researchers we can understand the operation of a network through describing the actors (Akrich \& Latour 1992:259). A script may be as simple 
as "close the door" or a million line computer program. The design of technical artifacts (quasi-objects) involves delegation of actions to various actors by inscribing. This process is complicated with a collection of script based activities such as prescription and proscription (which say what a particular actor will allow or forbid - the actor's "morals"), subscription (when an actor accepts a script), pre-inscription (the skills, knowledge or attitudes which we assume the actor already has) and circumscription (which places a boundary around the situation so we don't have to deal with the whole world), all of which may be ascribed to a particular situation by researchers. Translation can also be described as transcription. The point is to get another actor or network of actors to do my work for me. Whether the actors chosen are people, organisations or machines is a question of design; there is no essential difference, or at least any such difference is bracketed. In many cases the network is a mixture of people, organisations and machines, a hybrid.

For Latour the advantage of describing such hybrids in terms of actors, scripts and interactions is that we may be able to go a long way towards understanding the trajectory of power/knowledge networks without having to call on "external" forces such as scientific or social progress (Latour 1993:64). By taking the hybrids seriously as simultaneously real (natural), discursive (semiotic) and social (human) we can use our discoveries to feed back into our discrete theories of science, linguistics and sociology (Latour 1993:81). Modernist theory, by grounding explanation in either physical or social science (but never both) has denied the existence of hybrids and has allowed them to proliferate without control (Latour 1993:49-50). If we explain the development of graphic user interfaces for computers by the atomic structure of silicon or by the inherent greed of man's soul we have said nothing specific to this particular phenomenon; some timeless principles have simply worked themselves out (why now?). But if we concentrate on the networks of actors and translations, if we can relate the cleverness of the graphics programmers, the struggle between operating systems, the invention of a mass market for computers, the speed of the processors, the computerisation of media production and numerous other phenomena, if we can tell a truly dynamic story, then we can see how eventually such stories may come to change both nature and society. (Latour 1993:87)

The scheme (of some real or imagined project manager) for inscribing actors with the appropriate scripts to assure success of the project is called a program; of course there will always be opponents with an anti-program and the fate of the project depends on overcoming or coopting these opponents. The complexity of many hybrid networks is a result of adding extra scripts to defeat potential anti-programs. At any moment we can gain an insight into the health of a project by estimating the strength of the alliances which are 
necessary for project success. An example of this at an early stage of our case study project is given in figure 2 .

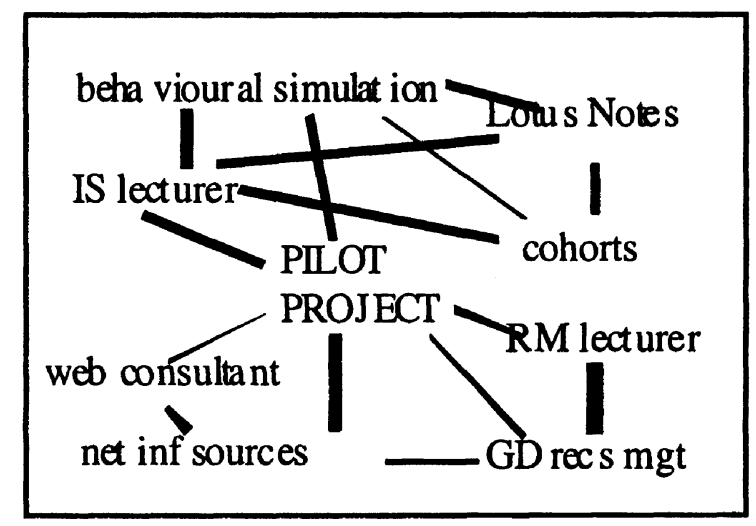

Figure 2. Early Alliances

Here the strength of alliances between the various actors is indicated by the thickness of the lines. In this diagram the (not yet fully existing) Pilot Project has a number of immediate allies, including three humans (the lecturers in Information Systems and Records Management, and the web consultant), a subject (network information sources) and a course (Graduate Diploma in Records Management). Two indirect and not so reliable allies are a software system (Lotus Notes) and a group learning activity (behavioural simulation). The final actor "cohorts" (groups of students who study together during several semesters) is a concept more or less deliberately introduced by the lecturer in Information Systems to gain support for the behavioural simulation and Lotus Notes. We can see that this does reinforce the alliance between these two actors; the actors who might be enrolled specifically in support of "cohorts" are not shown in this diagram.

Part of the inscription process involves some form of translation. If we want a pool gate to follow the script "keep children out" we might translate that to "have your latch two metres high". The translation is necessary because different actors base their meanings in different discourses. For the purposes of analysis of our case study material we imagined that a script in some neutral language (eg a statement in the minutes of a meeting) was embedded in an actor and then interpreted within one discourse or another, leading to action (figure 3 ).

Here we open up the question of interpretation by considering discourses as "external" networks. To avoid trying to understand everything at once we normally consider the actor network for a particular setting or situation, such as LaPerouse's explorations (Latour 1987:215-232) or the development of a computer-based information system. We surround the situation with a 
boundary and imagine that actors outside don't matter, or can be classified as "constraints". But there are networks extending (and folding back) to infinity. We can make the "constraints" a little more realistic by acknowledging their generative networks but restricting these networks to particular issues, "political networks" or "economic networks" for instance. In this research we concentrate on "conceptual networks", which are identified with Foucault's discourses. A script carried by some actors in the current setting can find its meaning in another network which we call a discourse. In an IS development project some scripts may refer to the discourse of accounting, others to the discourse of electronics. The same words may be used but the meanings may be incommensurable. At the same time, however, meaning becomes available within the local network. As design work continues a script such as "process the pay slips efficiently" may come to have its own meaning within the project, a meaning shared by the designers but no longer congruent with its meaning in the designers' home discourses such as accounting or computer science. This building of local languages, the possibility of beginning a new discourse, is an important aspect of both the difficulty and excitement of designing information systems.

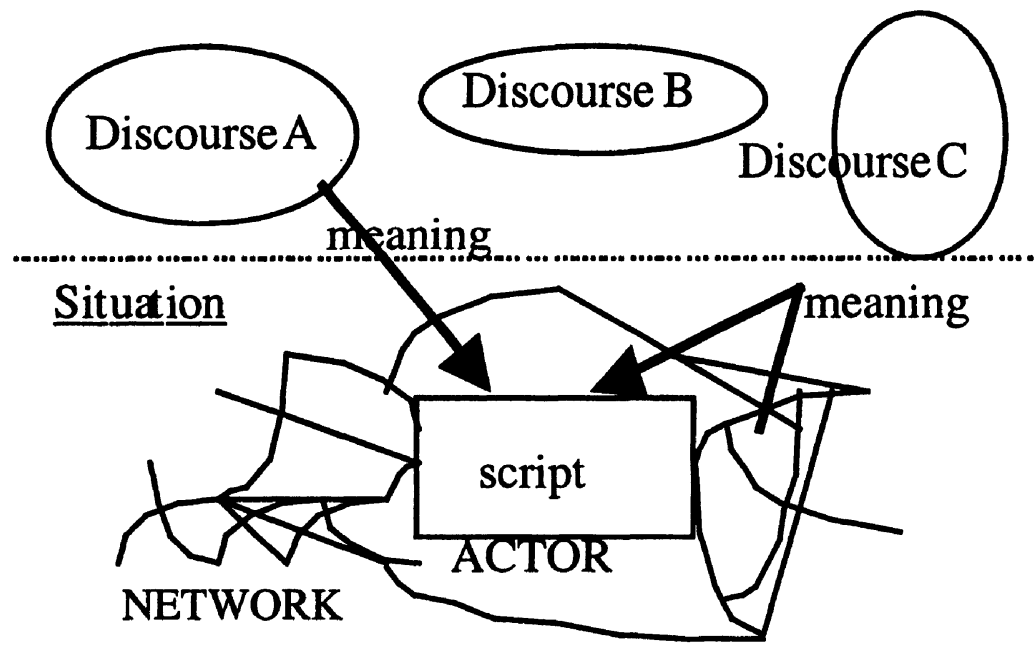

Figure 3. Script and Discourse

\section{SCRIPT TRANSLATION IN ACTION}

The above analysis was applied to the Flexible Delivery Pilot Project. A number of actors were identified including certain academic and nonacademic staff of the university, organisational units such as the computer 
centre, particular courses and class exercises, software packages, and concepts such as "flexible learning" and "group learning". Alliances among these actors were traced and programs promoting scripts such as "involve students" and "support work groups" were evaluated. An attempt was made to understand why the majority of stakeholders regarded the project as a success. The combination of ANT and Foucault's discourse theory proved to be a powerful tool, providing a convincing overview of the project while at the same time incorporating much interesting detail. Our major concern in this paper is to show how the mistranslation of scripts between actors managed to preserve ambiguity and contribute to project success.

An example of interpretation through reference to different discourses was the case of "framework". In the Introduction we noted that the aim of the Flexible Delivery Pilot Project was to produce a framework for supporting flexible learning within the university. In an early email exchange the Research Fellow in Communications (the nominal project manager in the early stages of the project) said "we need a brief 'concept statement' outlining the functions of the learning framework". In the formal project proposal this was described as "learning frameworks, eg electronic tutorials, electronic meetings, electronic case studies, innovative forms of electronic lecture material presentation, lower-tech forms of flexible delivery of educational materials". The emphasis here is on educational activities. The other participant in the email exchange, the web consultant, responded that "... one of the purposes of the metaphor or student interface is to provide students with conceptual clues that enable students to quickly orient themselves to the online environment and find the tools they need ..." and continued with some fairly technical details. Here the tension between interpretation in educational and technical discourses is already apparent. It appears that from an educational point of view a framework might provide a particular type of educational experience, such as a virtual tutorial or an online quiz. In technical discourse exactly the same words could be used, but with different conceptual links. A quiz, for instance, might be seen technically as a problem of screen layout, data base design and scoring algorithms. It is not the case that work can be clearly divided between educational design and technical design. At the most detailed level, such as specifying the maximum length of answers allowed, educational and technical discourses interact, often within the same person.

We have already noted how many project participants avoided clarification of apparently key concepts. This was played out in project working group meetings, where agenda items to discuss the nature of the project were invariably deferred until the next meeting. For instance, the minutes of the last ever formal meeting of the project working group end "The meeting had to end at this point without any ideas about the student 
interface to their learning space being discussed. This will be the main agenda item at the next meeting". Exactly the same point was made at the end of several earlier meetings. To explain how this situation could be maintained we looked more closely at the process of script translation. Figure 3 shows the translation of a script by a single actor with a choice of different reference discourses. This diagram is repeated for every actor in the network, with some actors sharing the same discourse. As scripts move from one actor to another (through apparently successful inscription) they need to be interpreted by the recipient. In our case study this happened at one (or both) of two levels, as shown in figure 4. Espoused scripts such as "support flexible delivery" were apparently subscribed to by new recruits while still retaining the script's identity. We suppose (though this is hard to test) that these were "anchored" or personalised by various actors through some process of internal translation, possibly through reference to a preferred discourse. These then emerge as (different) scripts-in-use, analogous to Argyris's (1978) theories-in-use. The translation/betrayal of these scripts-inuse seems to happen externally in the network rather than within the actors. Thus we have conceptually two networks, one of espoused scripts and one of scripts-in-use. It is not clear how these two levels interact, but it is certain that neither can be understood independently. This variety of translation locations makes it extremely difficult to produce a model which captures the knowledge in the development network. Some translation is internal to the actors, some takes place unnoticed in the empty spaces between actors.

\section{espoused script}

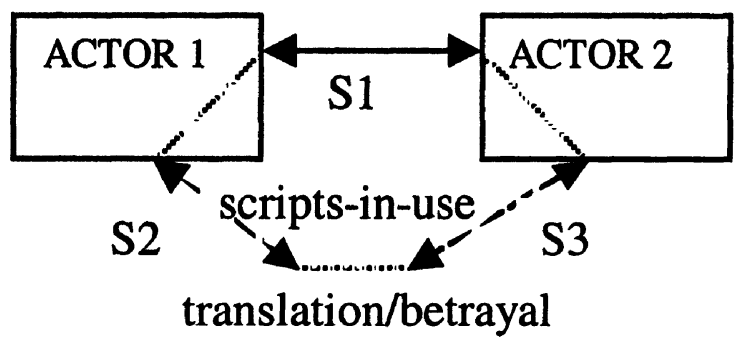

Figure 4. Two levels of Network

These translations could be regarded as betrayals, in the first case through the perversity or ignorance of actors, in the second through lack of a common language. Soft and hard systems development methodologies respectively claim to deal with one or the other of these sources of 
mistranslation. Theoretically, unless we specify some super actor (such as the project manager) whose discourse is dominant, there can be no distinction between translation and betrayal. The human participants in the Pilot Project were not particularly concerned about this possibility of mistranslation, generally assuming that it occurred but not showing much interest in where or how ("that's politics!").

These betrayals and the consequent ambiguity can in fact be used to maintain stability in the project alliance. In the case study a major part of the non-technical activity was devoted to having people "get with the program" that is to the phases of interessement and enrolment, where actors are first attracted to the project, and then retained through the cultivation of alliances and common interests. This was done through a small number of mass meetings, intermittent working group meetings, some informal discussion and negotiation with those who could influence higher level forums which were apparently outside the scope of the project network. The purpose of the mass meetings was to establish a surface consensus in support of the project. Often this is thought of as a "shared vision" and, as in this case, is relatively content free. In a more extraverted organisation this vision might be expected to generate enthusiasm; in a university it seems to generate discussion and cynicism, but it still puts the project on the agenda. (The reactions of different personality types to "visions" presents fascinating possibilities which we are not able to discuss here.) The working group meetings had more of an "agree to disagree" function. Here the actors attempted to steer the project towards their pre-existing interests according to the "garbage can" theory of problem definition, fitting the project requirements to their pre-conceived solutions (March and Olsen 1976). We can see that "packaged solutions" do not just come as software.

This combination of superficial consensus and suppressed conflict fits the model of figure 4 . The art of promoting a project involves both finding the vague concepts on which we can all agree and recognising the currently conflicting specific scripts which can be linked through mistranslation. In the case study mass meetings of potential users worked in the first mode, the project working group in the second; informal discussions dealt with both modes within the network, while exercises in influencing higher forums could be seen as providing connections in both modes in a different network (which we did not study in detail). One of the keys to success in this project was to separate the two modes of scripting. Many times at working group meetings there were attempts to force agreement on the meaning of particular concepts, goals or design elements. Whenever it became apparent that this was difficult the matter was deferred. This meant that a script was not translated at all (in which case it dropped out of the network - for example "seek commercial sponsorship for the web site") or a translation 
was allowed to develop without scrutiny (eg "support flexible delivery" to "put lecture notes on the web"). This unremarked translation/betrayal was crucial in maintaining "commitment" to the project. As Bismarck is reputed to have said: "Politics is like sausages; it's better not to know how it's done".

This commitment, however maintained, is realised in what Ciborra (1996) calls "care", in which a variety of actors take the trouble to include consideration of the project into their other activities. This includes supporting the project in various forums, considering interfaces with the project when designing or selecting software, adapting the project's scripts and concepts in their own discourse and, above all, feeling some sort of responsibility for the success of the project. Such care will only be provided by those who feel that the project has some chance of satisfying their needs.

Our evaluation of the project as a success can not be dealt with in detail here, but a number of criteria may be cited:

- the majority of the human actors involved in the project were satisfied with the outcome

- the original project sponsor (the deputy Vice-Chancellor) thought their original agenda had been advanced

- the unofficial project manager for the later parts of the project was quite pleased with the result

- each of the five project components in the original project proposal was achieved to some extent, though not completely and perhaps not in the way originally envisaged (if originally envisaged at all).

By the end of the project the "framework for supporting flexible learning" was seen to be neither a collection of possible educational activities, nor a user interface and underlying infrastructure, but:

- a book entitled Flexible Delivery: A Guide for Teaching Staff which included discussion of educational possibilities, available software, possible user interfaces and contact details for help

- a mechanism for using central funding to encourage flexible delivery projects

- an item in the University strategic plan supporting flexible delivery

- various unconnected pieces of software and course materials

The project had come up with its own local definition of "framework", a definition which had its strongest affinity to the discourse of University management. In retrospect this is not surprising, since the project was originally promoted and funded by management. This makes us wonder about the more usual expectations of project development, where the original objectives (or justification) might be framed in the discourse of top management, but the final product is expected to operate in the realm of computing or low level business processing. Perhaps this pre-programmed 
discourse shift makes failure (from management's point of view) highly probable.

\section{PROJECTS IN PRACTICE}

We do not hope to give detailed advice on negotiating project politics nor provide yet another methodology for requirements analysis. The participants in the case study seemed quite competent in both these areas and were in no need of our advice. We would rather wish to address students, academics and project managers. For students of IS we wish to normalise the idea of politics in IS development, to have them realise that politics is not something "added on" but an integral (and useful) part of IS analysis, design and construction. We (modestly) urge academics to concentrate on what is actually happening in IS development projects, not what they think ought to happen or what managers wish would happen. Both sets of advice apply equally to project managers but for them there are also some more specific points.

- don't imagine you have an authoritative or consensus overview of the project - agreement on wording does not mean agreement on meaning

- keep track of important scripts - if a script "drops out" it will probably become part of an anti-program and disrupt the project

- never imagine anything is settled - keep de-scribing

- patch up differences - don't cover them up

- let go - care about the project but don't identify with its success

These points are simply an acknowledgment that project development is an evolutionary process to which many contribute but which no one controls. Whether any project manager would be able to take this advice in the climate of most organisations is open to question. As Zuboff says:

This is a deeply political world in which the stakes are high - my career, my identity, my livelihood. It is as thick with fear, sacrifice, and the elation of a good kill as it is with the impulse toward community, dialogue, joy in work well done. It is a game with rules, and those rules derive from the particular properties of the managerial hierarchy. It is a game whose intensity is heightened by the nature of the very people that can be drawn into it. Too often their personal equilibrium depends on at least being in the game and, at best, winning. (Zuboff 1996)

On the other hand, a project manager with a record of keeping most stakeholders happy, even if they cannot be seen to be a hard competitor, might eventually become a valued member of the organisation. But if nobody is clearly in charge, how can anything ever work at all? How can we 
live on the Deleuzian plateau? We have already mentioned the care from committed actors which Ciborra (1996) says is essential for the survival of a system. Latour (1996) speaks of love for the project. By this he means that for sufficient actors the project ceases to be merely instrumental for their own programs and becomes an end in itself. We hope that when enough actors care for the project and for each other that something good will eventuate. This is not so unlikely, since the only even-handed definition of success is actor satisfaction.

The parasitic invaders seem set to succeed in their vile plans but, lets face it, any loose coalition of nerds, jocks, cheerleaders and loners is odds-on to expel the extraterrestrials. (Anderson 2001)

\section{REFERENCES}

Akrich, M. \& Latour, B. (1992) "A Summary of a Convenient Vocabulary for the Semiotics of Human and Nonhuman Assemblies" in Bijker, Wiebe E. \& Law, John (eds) Shaping Technology / Building Society, MIT Press, Cambridge MA

Anderson, D. (2001) Review of The Faculty, TV Guide, Sydney Morning Herald, 22nd October

Argyris, C. (1978) Organizational Learning, Addison-Wesley, Reading MA

Chaplin, C. (1936) Modern Times (film), United Artists

Ciborra, C.U. (1996) "Introduction: What does Groupware Mean for Organizations Hosting it?" in Ciborra, C.U. (ed) Groupware \& Teamwork: Invisible Hand or Technical Hindrance?, Wiley, Chichester

Davis, G.B. \& Olson, M.H. (1984) Management Information Systems, McGraw-Hill, New York

Deleuze, G. \& Guattari, F. (1988) A Thousand Plateaus, Athlone, London

Deleuze, G. \& Parnet, C. (1987) Dialogues, Athlone, London

Falkenberg, E.D., Hesse, W. \& Olive, A. (1995) Information Systems Concepts: Towards a Consolidation of Views, Chapman \& Hall, London

Foucault, M. (1972) The Archaeology of Knowledge, Tavistock, London

Foucault, M. (1980) Power/Knowledge, Pantheon Books, New York

Hawryszkiewycz (2001) Systems Analysis and Design (5 edn), Prentice Hall, Sydney

Latour, B. (1987) Science in Action, Harvard University Press, Cambridge MA

Latour, B. (1993) We Have Never Been Modern, Harvester, New York

Latour, B. (1996) ARAMIS or The Love of Technology, Harvard University Press, Cambridge MA

March, J.G. \& Olsen, J. (1976) Ambiguity and Choice in Organizations, Universitetvorlaget, Bergen

Noth, W. (1990) Handbook of Semiotics, Indiana University, Bloomington

Oehler (1987) "An Outline of Peirce's Semiotics" in Krampen, Martin et al (eds) Classics of Semiotics, Plenum Press, New York

Spinks, C.W. (1991) Peirce and Triadomania, Mouton de Gruyter, Berlin

Stamper, R. (1973) Information, Wiley, New York 
Stamper, R. (1992) "Signs, Organisations, Norms and Information Systems" in MacGregor, R. (ed) Proceedings of Third Australian Conference on Information Systems, Department of Business Systems, Wollongong

Winder, R.L., Probert, S.K. \& Beeson, I.A. (eds) (1997) Philosophical Aspects of Information Systems, Taylor \& Francis, London

Zuboff, Shoshana (1996) "Forward" in Ciborra, C.U. (ed) Groupware \& Teamwork: Invisible Hand or Technical Hindrance?, Wiley, Chichester 